\title{
Effect of denatured whey protein concentrate and its fractions on cheese composition and rheological properties
}

\author{
Véronique Perreault, ${ }^{\dagger} \dagger$ Nathalie Rémillard,‡ Denise Chabot,§ Pierre Morin,\# Yves Pouliot,* \\ and Michel Britten* $\ddagger^{1}$ \\ *STELA (Dairy Science and Technology Research Centre), Institute of Nutrition and Functional Foods (INAF), Université Laval, Quebec City, QC, \\ Canada, G1K 7P4 \\ †Centre de Recherche en Gastronomie, Institut de Tourisme et d'Hôtellerie du Québec, Montreal, QC, Canada, H2X 3P1 \\ ¥Saint-Hyacinthe Research and Development Centre, Agriculture and Agri-Food Canada, 3600 Casavant Boulevard West, Saint-Hyacinthe, QC, \\ Canada, J2S 8E3 \\ §Ottawa Research and Development Centre, Agriculture and Agri-Food Canada, 960 Carling Avenue, Ottawa, ON, Canada, K1A 0C6 \\ \#Research and Development Centre, Agropur Dairy Cooperative, Saint-Hubert, QC, Canada, J3Z 1G5
}

\begin{abstract}
The objectives of this study were (1) to assess the effect of a denatured whey protein concentrate (DWPC) and its fractions on cheese yield, composition, and rheological properties, and (2) to separate the direct effect of the DWPC or its fractions on cheese rheological properties from the effect of a concomitant increase in cheese moisture. Semihard cheeses were produced at a laboratory scale, and mechanical properties were characterized by dynamic rheometry. Centrifugation was used to induce a moisture gradient in cheese to separate the direct contribution of the DWPC from the contribution of moisture to cheese mechanical properties. Cheese yield increased and complex modulus $\left(\mathrm{G}^{*}\right)$ decreased when the DWPC was substituted for milk proteins in milk. For cheeses with the same moisture content, the substitution of denatured whey proteins for milk proteins had no direct effect on rheological parameters. The DWPC was fractionated to evaluate the contribution of its different components (sedimentable aggregates, soluble component, and diffusible component) to cheese yield, composition, and rheological properties. The sedimentable aggregates were primarily responsible for the increase in cheese yield when DWPC was added. Overall, moisture content explained to a large extent the variation in cheese rheological properties depending on the DWPC fraction. However, when the effect of moisture was removed, the addition of the DWPC sedimentable fraction to milk increased cheese complex modulus. Whey protein aggregates were hypothesized to act as active fillers that physically interact with the casein matrix and confer rigidity after pressing.
\end{abstract}

Received December 16, 2016.

Accepted February 25, 2017.

${ }^{1}$ Corresponding author: michel.britten@agr.gc.ca
Key words: whey protein, cheese, moisture, rheological properties, pressing

\section{INTRODUCTION}

For economic reasons, the fortification of cheese milk with a denatured whey protein concentrate (DWPC) is a common practice in Canadian large-scale cheese plants. Introducing DWPC into cheese milk generally increases cheese yield, a change that is attributed mostly to higher water retention (Banks and Muir, 1985; Lebeuf et al., 1998; Schenkel et al., 2011) and to higher protein recovery from DWPC-fortified milk (Banks and Muir, 1985; Lebeuf et al., 1998). A DWPC contains various components that interfere in distinct ways with rennet gel formation and contraction (Perreault et al., 2017) and could affect cheese properties. These components can be divided into 3 main categories: the sedimentable or insoluble protein aggregates, the diffusible fraction (which is composed mainly of soluble minerals), and the nonsedimentable or soluble protein complexes (which form concurrently during the heating and shearing of whey protein concentrate).

Cheese can be described as a particle-filled gel, also called a composite gel or gelled emulsion (Yang et al., 2011). Similar to fat globules, insoluble whey protein aggregates end up embedded in the casein network during milk coagulation (Desai and Nolting, 1995; Steffl et al., 1999). Some studies suggest that microparticulated whey proteins (Simplesse, CP Kelko Germany GmbH, Großenbrode, Germany) act as non-interacting fillers (Desai and Nolting, 1995; Schenkel et al., 2013), improve the texture of reduced-fat semihard cheese by inducing irregularities in the continuous protein matrix (Schenkel et al., 2013), and improve cheese melting properties through a ball-bearing effect (Schenkel et al., 2013). However, negative effects of DWPC on cheese melting properties have also been reported (Mead and 
Roupas, 2001; Schenkel et al., 2011). It is difficult to determine the direct effect of DWPC on cheese texture because it increases moisture content, and that increase has a strong influence on cheese mechanical properties (Wodecki et al., 1984; Lucey et al., 2003). Various process adjustments can be used to control moisture retention in DWPC-fortified cheese (Schenkel et al., 2011, 2013), but these adjustments could potentially affect the cheese's final composition, structure, and mechanical properties.

Adding DWPC can alter the mineral composition of cheese milk. The influence of minerals on rennet coagulation and cheese texture is well documented. Increasing the calcium concentration in milk is known to promote rennet coagulation (Dalgleish, 1983; Sandra et al., 2012) and increase gel firmness (Sandra et al., 2012). Higher mineral levels in cheese are associated with harder texture (Lucey and Fox, 1993) and poor melting properties (Joshi et al., 2003). Recently, some authors pointed out that small soluble protein complexes formed during the high-heat treatment of milk (Kethireddipalli et al., 2010, 2011) or whey protein dispersions (Giroux et al., 2015) could interact with renneted casein micelles and interfere with the coagulation process.

In a recent study, a commercial DWPC was fractionated, and the effects of the fractions on rennet-induced coagulation and gel contraction properties were determined (Perreault et al., 2017). Sedimentable aggregates from the DWPC acted essentially as non-interacting filler particles in a rennet gel, and little effect of the minerals was shown. However, the soluble protein complexes were shown to reduce rennet gel formation and contraction, suggesting that this fraction interacted with renneted casein micelles and interfered with the coagulation process. To complement that previous work, the effect of DWPC fractions on the mechanical properties of the final cheese matrix remains to be determined. The objectives of the present study were therefore (1) to assess the effect of DWPC and its fractions on cheese yield, composition, and rheological properties, and (2) to separate the direct effect of the DWPC or its fractions on cheese rheological properties from the effect of a concomitant increase in cheese moisture. The pressing conditions were controlled to isolate the DWPC effect from the moisture effect on cheese mechanical properties.

\section{MATERIALS AND METHODS}

\section{Materials}

Nonfat dry milk was supplied by Agropur Dairy Cooperative (Granby, QC, Canada). Milk protein isolate
(MPI) containing $81.8 \%$ protein (wt/wt), as specified by the manufacturer, was obtained from Idaho Milk Products (Jerome, ID). Fresh raw cream was provided by Agropur Dairy Cooperative (Saint-Hyacinthe, QC, Canada). A DWPC was produced at an industrial scale by the heat denaturation of whey protein concentrate according to Agropur's proprietary process; the DWPC was subsequently spray-dried as described in a previous study (Perreault et al., 2016). The direct vat set thermophilic starter F-ES i484 was supplied by Chr. Hansen (Milwaukee, WI), distributed in $500-\mu \mathrm{L}$ aliquots, and kept frozen $\left(-85^{\circ} \mathrm{C}\right)$ until use. Chy-Max Extra with a minimum 600 international milk clotting units (IMCU)/mL (Chr. Hansen) was used as coagulant.

\section{Preparation of Ingredients and Fractions}

The nonfat dry milk was hydrated to a $3.2 \%$ (wt/ wt) total protein concentration, and the MPI and the powdered DWPC were hydrated to a $10.0 \%$ (wt/wt) total protein concentration, as described in a previous study (Perreault et al., 2016). The dispersions were stored overnight at $4^{\circ} \mathrm{C}$. The composition of the cream was determined by infrared analysis (MilkoScan FT120; Foss North America, Brampton, ON, Canada), and to ensure consistency in milk standardization, the fat concentration of the cream was reduced to $38 \%$ by dilution with skim milk.

The preparation of the DWPC fractions was detailed in a previous study (Perreault et al., 2017). Briefly, dialysis was used to isolate the soluble mineral component of the DWPC. Deionized water was dialyzed against the DWPC dispersion for $2 \mathrm{~d}$ at $4^{\circ} \mathrm{C}$ using dialysis tubing with a 6 - to $8-\mathrm{kDa}$ molecular weight cutoff (Spectrum Laboratories, Rancho Dominguez, CA). As a control, milk dialysate was prepared in the same way from standardized milk. Ultracentrifugation at $31,100 \times g$ for $1 \mathrm{~h}$ at $20^{\circ} \mathrm{C}$ (Kethireddipalli et al., 2010) was used to separate aggregates (pellet) from the total soluble component of the DWPC (supernatant). The supernatant contained not only soluble minerals but also soluble complexes. The pellet was redispersed in milk dialysate in equivalent proportions (wt/wt). All fractions were stored at $4^{\circ} \mathrm{C}$ until analysis. The composition and characteristics of the DWPC fractions were presented in a previous study (Perreault et al., 2017), and some of that information is reported in Table 1.

\section{Cheese Milk Standardization, Inoculation, and Renneting}

For all experiments, milk fat content was adjusted to $3.4 \%$ (wt/wt). For the first set of experiments, DWPC concentration in the nonfat fraction of cheese milk was 
adjusted to $0,0.25,0.50$, or $0.75 \%$ (wt/wt), and total protein concentration in the nonfat fraction was standardized to $4.2 \%$ with MPI dispersion. Protein and fat concentrations were determined after cheese milk standardization and were only slightly lower than the target values for fat, with $3.36 \pm 0.04 \%$ and slightly higher for protein in the nonfat fraction, with $4.26 \pm 0.02 \%$. For the second set of experiments, the $0.50 \%$ DWPC condition was used, and the DWPC was replaced by an equal mass of one of its fractions (dialysate, supernatant, or pellet dispersion) or of milk dialysate as the control.

Once the ingredients (skim milk, MPI and DWPC dispersions, and cream) had been mixed at $4^{\circ} \mathrm{C}$, the cheese milk was batch-pasteurized at $65^{\circ} \mathrm{C}$ for $30 \mathrm{~min}$ under 120-rpm orbital agitation in a water bath and then cooled to $34^{\circ} \mathrm{C}$. Calcium chloride was added to a final concentration of $0.02 \%$, and the $\mathrm{pH}$ was adjusted to 6.50 with $40 \%$ lactic acid. Milk was then maintained at $34^{\circ} \mathrm{C}$ for $15 \mathrm{~min}$ before inoculation with a direct vat set starter (aliquot thawed within 3 min, just before pipetting) at a rate of $0.016 \%$ (vol/wt). Then milk was left to mature at $34^{\circ} \mathrm{C}$ under gentle agitation until the $\mathrm{pH}$ reached 6.45 (about 15-30 $\mathrm{min}$ ). The rennet was diluted 1:10 in deionized water and added to a final concentration of $0.01 \%$.

\section{Miniature Cheese Production}

Miniature cheeses were produced according to the method described by Morin et al. (2008) with some adjustments. First, $144 \mathrm{~g}$ of standardized milk, to which rennet had been added, was quickly poured into a $12-\times 12-\mathrm{cm}$ stainless steel cheese mini-vat, with a Plexiglas lid layered with cheesecloth to allow whey recovery. The covered vat was immediately placed into a thermostatically controlled orbital shaking water bath at $34^{\circ} \mathrm{C}$, without agitation. After $30 \mathrm{~min}$, the gel was cut using a stainless steel knife with 11 blades spaced 1 $\mathrm{cm}$ apart, to obtain $1-\mathrm{cm}^{3}$ curd particles. The curd was then maintained at $34^{\circ} \mathrm{C}$, first statically for $1 \mathrm{~min}$ followed by 50-rpm orbital agitation for $4 \mathrm{~min}$. Then, still under 50-rpm agitation, the temperature was gradually raised to $42^{\circ} \mathrm{C}$ over $30 \mathrm{~min}$, allowing the serum $\mathrm{pH}$ to reach $6.10 \pm 0.10$. Drainage was then carried out by reversing the vat to recover whey in the vat lid and by maintaining the system at $42^{\circ} \mathrm{C}$ in the water bath for 70 to 75 min without agitation, allowing the curd to reach a target $\mathrm{pH}$ of 5.30 .

For the pressing stage, the drained curd was transferred to plastic $50-\mathrm{mL}$ centrifuge tubes with a $25-\mathrm{mm}$ internal diameter (Fisherbrand; Fisher Scientific Ltd., Saint-Laurent, QC, Canada). The bottom conical part of the tube was filled with resin (Resin Crystal; Pebeo Industries, Gemenos, France) to obtain a cheese curd that was perfectly cylindrical in shape after pressing (Figure 1). Centrifugation was performed at 5,000 $\times g$ for 30 min at $25^{\circ} \mathrm{C}$ using an Avanti J-26 XPI ultracentrifuge with a JS-7.5 swinging-bucket rotor (Beckman Coulter, Mississauga, ON, Canada). Whey from drainage and whey from centrifugation were pooled. The cheese was carefully removed from the tube and rolled on an absorbent paper to eliminate surface whey. The mass of the cheese was recorded, and the actual yield was calculated using the following equation:

$$
\begin{gathered}
\text { Actual yield }(\%)= \\
(\text { mass of curd } / \text { mass of milk }) \times 100 .
\end{gathered}
$$

Pressing by centrifugation was chosen because it induces a pressure gradient along the tube caused by variation in the centrifugal force (Figure 1), which results in a moisture gradient in the cheese. This approach allows the production of a cheese cylinder with homogeneous composition except for moisture, which decreases with increasing distance from the rotation axis of the centrifuge. No change in the ionic strength is expected because the concentration of dissolved solids in the aqueous phase is not affected by centrifugation. Disks can then be cut from the cylinder to study the properties of cheese samples with the same protein to fat ratio, the same aqueous phase composition, but different moisture contents.

Table 1. Mean protein composition and characteristics of the denatured whey protein concentrate (DWPC) and its fractions ${ }^{1}$

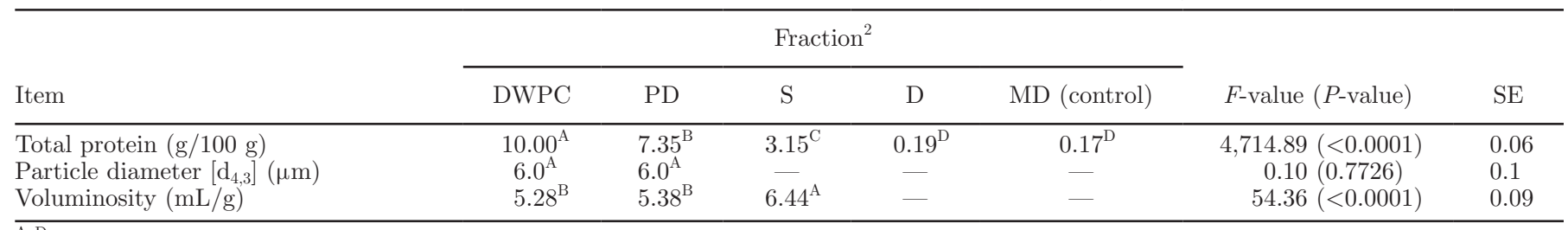

\footnotetext{
${ }^{\mathrm{A}-\mathrm{D}}$ Values within a row that do not share a common superscript differ significantly $(P<0.05)$.

${ }^{1}$ These results were presented elsewhere (Perreault et al., 2017). $F$-value, $P$-value (in parentheses), and SE correspond to the effect of the nature of the fraction on its composition and characteristics.

${ }^{2} \mathrm{PD}=$ pellet dispersion; $\mathrm{S}=$ supernatant; $\mathrm{D}=$ dialysate; $\mathrm{MD}=$ milk dialysate.
} 


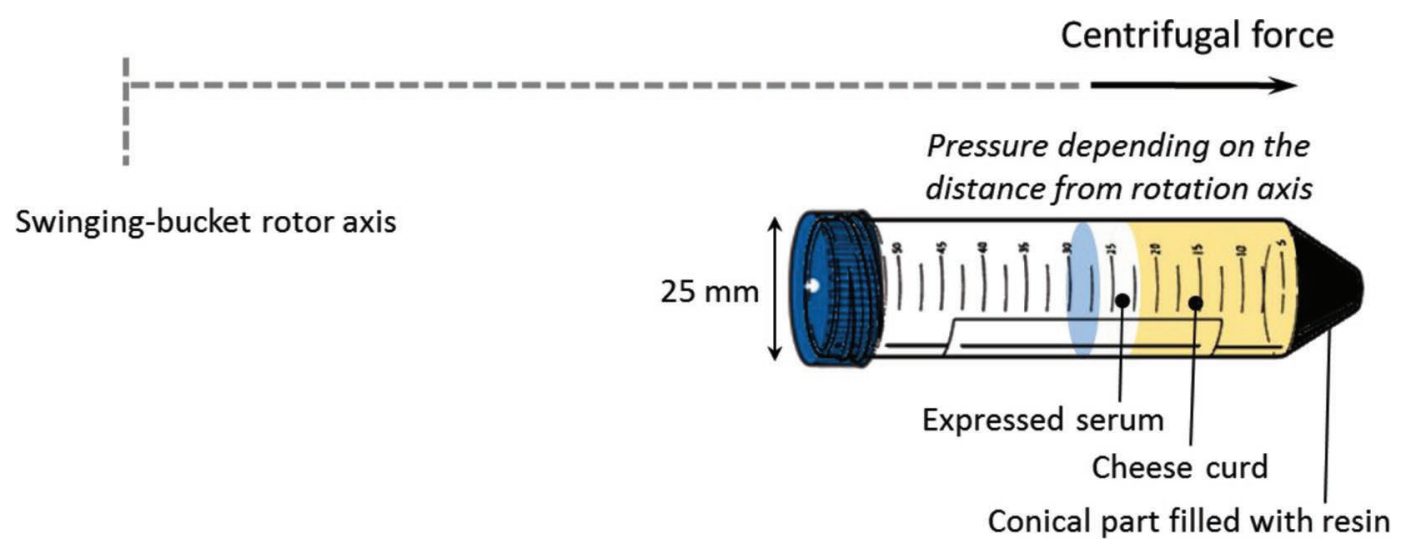

Figure 1. Illustration of the pressing-by-centrifugation method. A 50-mL centrifuge tube with a 25-mm internal diameter was used. The bottom conical part of the tube was filled with resin to obtain a cylindrical cheese curd with a flat bottom. The use of a swinging-bucket rotor made it possible to generate a pressure gradient from top to bottom of the curd cylinder (perpendicular to the rotation axis). Color version available online.

Milk composition and whey composition were determined by infrared analysis (MilkoScan FT-120; Foss North America). The internal calibration for milk analysis was corrected with commercially certified milk samples (Valacta, Sainte-Anne-de-Bellevue, QC, Canada) and the internal calibration for whey analysis was verified with representative whey samples produced in our laboratory and analyzed for protein and fat by Kjeldahl and Mojonnier methods. Curd fat content and protein content were obtained through mass balance calculations. Retention coefficients were calculated for fat and proteins using the following equation:

$$
\begin{gathered}
\text { Retention }(\%)=100 \times[1-(\% \text { fat or protein } \\
\text { in whey } / \% \text { fat or protein in milk })] .
\end{gathered}
$$

\section{Cheese Handling for Rheometry and Moisture Determination}

After production, the cheese cylinders were wrapped hermetically in plastic film and stored at $4^{\circ} \mathrm{C}$ for $7 \mathrm{~d}$ to allow proper fusion of the cheese grains. Preliminary experiments had shown that this storage period does not alter the moisture gradient (V. Perreault, unpublished data). Three cheese disks (3 mm thick) were then cut from each cylinder using a cylindrical guide with cheese-cutting wires. The first disk was cut at $3 \mathrm{~mm}$ from the bottom end of the cylinder, and the distance between disks was set to $12 \mathrm{~mm}$. Rheological analysis was performed immediately after sampling. Because moisture content could not be determined directly on the disks used for rheological analysis, moisture content was averaged from the moisture content of the 2 adjacent slices (3 $\mathrm{mm}$ thick) taken from the cylinder.
Moisture in these cheese slices was determined by gravimetry after dehydration in a forced-air oven at $100^{\circ} \mathrm{C}$ for $5 \mathrm{~h}$ (AOAC International, 2005b). Overall cheese moisture was calculated by averaging the moisture content of all individual slices.

\section{Proteolysis Index Measurement}

The proteolysis rate in the cheeses after $7 \mathrm{~d}$ of storage was evaluated by measuring water-soluble nitrogen (Watkinson et al., 2001) on whole cheese samples. The cheese was finely ground using a small food processor. Samples were set aside for total protein composition analysis and for soluble nitrogen extraction; the samples were stored at $-85^{\circ} \mathrm{C}$ in sealed tubes until analysis. The soluble nitrogen was extracted by adding $8 \mathrm{~g}$ of deionized water to $4 \mathrm{~g}$ of ground cheese. The cheese and water were first homogenized using an Ultra-Turrax homogenizer with an S25N-10G dispersing element (IKA, Wilmington, NC) at 13,000 rpm for $2 \mathrm{~min}$. The sample was heated at $40^{\circ} \mathrm{C}$ for $1 \mathrm{~h}$ and then centrifuged at $3,000 \times g$ at $4^{\circ} \mathrm{C}$ for 30 min (BeckmanCoulter centrifuge, JA-12 rotor; Beckman-Coulter, Mississauga, ON, Canada). The upper solid-fat phase was removed, and the supernatant (the aqueous phase) was filtered through a VWR grade 474 filter paper (VWR International, Ville Mont-Royal, QC, Canada). The pellet was covered with $8 \mathrm{~g}$ of deionized water, and the extraction steps (homogenization, heating, centrifugation, and filtration) were repeated; the filtered supernatant was pooled with the previous one. Water-soluble nitrogen on d 7 (WSN7) and total nitrogen (TN) in the cheese were determined by analyzing the extract and the initial cheese, respectively, using the Kjeldahl method (AOAC International, 2005a). Water-soluble 
nitrogen was reported as a percentage of TN (WSN7/ $\mathrm{TN} \times 100)$.

\section{Microscopy}

Confocal Laser Scanning Microscopy. Samples for confocal laser scanning microscopy were taken at $15 \mathrm{~mm}$ from the bottom of each cheese cylinder. On a refrigerated surface, the cheese was cut longitudinally into $3 \times 3 \times 4$-mm sticks. A method inspired from other studies (Auty et al., 2001; Ayala-Bribiesca et al., 2016) was adapted to enhance the visualization of the whey protein particles within the cheese matrix. The cheese sticks were frozen at $-16^{\circ} \mathrm{C}$ on cold stubs with O.C.T. compound medium (Tissue-Tek, Sakura Finetek USA Inc., Torrance, CA) in a Cryocut E Reichert Jung cryostat (Leica Microsystems, Vienna, Austria). Slices $14 \mu \mathrm{m}$ thick were cut longitudinally and placed in a $1 \%$ Nile blue A staining solution on cold coverslips, which were subsequently kept for $1 \mathrm{~min}$ at $-16^{\circ} \mathrm{C}$. The coverslips were then mounted on cold glass slides and kept at $4^{\circ} \mathrm{C}$ for $10 \mathrm{~min}$ before observation. The samples were observed rapidly under a Zeiss LSM 510 Duo confocal microscope using an $\alpha$ Plan-Apochromat $63 \times \mathrm{NA}$ 1.46 objective (Carl Zeiss MicroImaging, Göttingen, Germany). Nile blue A was used to allow simultaneous staining of fat and protein; fat was detected with an Argon/2 laser line at $488 \mathrm{~nm}$ for excitation and 530 to $750 \mathrm{~nm}$ for emission, and protein was detected with a HeNe laser line at $633 \mathrm{~nm}$ for excitation and 650 to $750 \mathrm{~nm}$ for emission. The images were recorded and processed using ZEN 2009 software (Carl Zeiss GmbH, Jena, Germany). For all the cheeses, 12 samples were taken and observed, and representative images were then selected.

Scanning Electron Microscopy. The scanning electron microscopy samples were taken at $15 \mathrm{~mm}$ from the bottom of each cheese cylinder. In a $4^{\circ} \mathrm{C}$ room, the cheese was cut longitudinally into $3 \times 3 \times 4$-mm sticks using a razor blade. The samples were then handled following the procedure described by Ayala-Bribiesca et al. (2016). The samples were immediately immersed in a $0.1 M$ sodium cacodylate buffer at $\mathrm{pH} 7.2$ and containing $2 \%$ glutaraldehyde (18426; Ted Pella, Redding, $\mathrm{CA}$ ) and were kept under weak agitation for $2 \mathrm{~h}$ at room temperature for the purposes of protein fixation. After the buffer was removed, all the stick samples were dehydrated in steps of 15 min each in a graded series of ethanol concentrations $(30,50,70,80,90,95,100$, and $100 \%)$. The samples were defatted using hexane for 3 consecutive steps of $15 \mathrm{~min}$ each and were then freezefractured in liquid nitrogen and dried with a critical point dryer (Biodynamics Research Corp., Rockville,
MD). The samples were subsequently mounted on aluminum stubs and covered with a 10-nm layer of gold using an Emitech K550X sputter coater (Quorum Technologies, Kent, UK). The observations were performed using a Quanta 600 scanning electron microscope (FEI Company, Brno, Czech Republic) operating under high vacuum at 5 or $20 \mathrm{kV}$ and a working distance between 6 and $10 \mathrm{~mm}$. For each cheese, 10 fields were observed, and representative micrographs were then selected.

\section{Rheometry}

Frequency Sweep. On d 7, dynamic oscillatory measurements were performed using a controlled stress rheometer (Physica MCR 301; Anton Paar GmbH, Graz, Austria) equipped with 25-mm parallel plate geometry (PPS25; Anton Paar $\mathrm{GmbH}$ ). Sandpaper was glued to the bottom plate of the rheometer to prevent slippage. For each experimental cheese, 3 disks (25 $\mathrm{mm}$ in diameter and $3 \mathrm{~mm}$ in height) that had been sampled as described above were analyzed. To limit evaporation from the sample, the periphery of the cheese disk was carefully coated with a thin layer of mineral oil using a cotton swab, and a protection hood covered the sample during the test. The temperature was set to $20^{\circ} \mathrm{C}$ and maintained with a Peltier thermal control system (C-PTD200; Anton Paar GmbH). The cheese disk was compressed at $1 \mathrm{~N}$ normal force for a 5-min equilibration period before the frequency sweep experiment started. A constant strain amplitude $(0.1 \%)$ was applied to the sample, and the oscillation frequency was increased from 0.5 to $10 \mathrm{~Hz}$ over 10 min. The viscoelastic parameters were monitored, and the data were collected with RheoPlus 3.40 software (Anton Paar $\mathrm{GmbH}$ ). The complex modulus $\left(\mathrm{G}^{*}\right)$ and the loss tangent $(\tan \delta)$ were recorded as a function of oscillation frequency, and the mechanical spectrum was characterized using Equations 3 and 4 (Subramanian et al., 2006; Banville et al., 2014), as follows:

$$
\begin{aligned}
\mathrm{G}^{*} & =\mathrm{G}^{*}{ }_{1 \mathrm{~Hz}} \omega^{\mathrm{k}}, \\
\tan \delta & =\tan \delta_{1 \mathrm{~Hz}} \omega^{\mathrm{k}},
\end{aligned}
$$

where $\omega$ is the frequency $(\mathrm{Hz}) ; \mathrm{G}^{*}{ }_{1 \mathrm{~Hz}}$ and $\tan \delta_{1 \mathrm{~Hz}}$ are the complex modulus at $1 \mathrm{~Hz}$ and the loss tangent at $1 \mathrm{~Hz}$, respectively; and $\mathrm{k}$ is the power-law index, which represents the frequency dependence of the moduli between 0.5 and $10 \mathrm{~Hz}$.

Temperature Sweep. After frequency sweep measurement, the compression of the cheese disk was adjusted again to $1 \mathrm{~N}$ normal force for a 2-min equilibration period at $20^{\circ} \mathrm{C}$ before the temperature sweep 
experiment started. A constant strain amplitude (0.1\%) was applied at an oscillation frequency of $1 \mathrm{~Hz}$. The temperature was raised at $5^{\circ} \mathrm{C} / \mathrm{min}$. The $\mathrm{G}^{*}{ }_{1 \mathrm{~Hz}}$ and the $\tan \delta_{1 \mathrm{~Hz}}$ were recorded at $60^{\circ} \mathrm{C}$.

\section{Statistical Analyses}

In the first experiment, miniature cheeses were produced using 4 levels of DWPC proteins in milk (0, $0.25,0.50$, or $0.75 \%$ ). In the second experiment, miniature cheeses were produced with different fractions of DWPC (dialysate, ultracentrifugation supernatant, or pellet dispersion in milk dialysate) or milk dialysate as the control. The entire experiments were repeated at least 3 times.

All cheeses were tested for yield and composition, and the data were analyzed according to a completely randomized design.

For all the cheeses, the frequency sweep test and the temperature sweep test were performed on samples taken at 3 different positions in the cheese cylinder after centrifugation (bottom, middle, and top). Complex modulus $\left(\mathrm{G}^{*}\right)$ data were subjected to logarithmic transformation for better homogeneity of variance. Data were analyzed as a factorial split-plot design, with the position of the sample in the subplot.

An ANOVA was performed in SAS software (SAS Institute Inc., Cary, NC). The effect was considered significant when $P \leq 0.05$. A Fisher's protected least significant difference test was used to evaluate the differences between treatments at a significance level of
0.05. Error bars in the graphs indicate standard errors obtained from the statistical models.

\section{RESULTS AND DISCUSSION}

\section{Effect of DWPC Level}

Cheese Yield and Composition. Cheese yield and composition as a function of the DWPC level are presented in Table 2. Increasing the DWPC level in milk linearly increased cheese yield $(\mathrm{dYield} \% / \mathrm{dDWPC} \%=$ $2.89 ; P<0.0001)$ and cheese moisture (dMoisture\%/ dDWPC $\%=8.90 ; P<0.0001)$; as expected, cheese yield is strongly correlated with cheese moisture $(\mathrm{r}=$ 0.993). Similar results were reported by several authors (Banks and Muir, 1985; McMahon et al., 1996; Fenelon and Guinee, 1997; Lebeuf et al., 1998; Mead and Roupas, 2001; Schenkel et al., 2011). As a result of the higher moisture content, increasing the DWPC level in milk also significantly decreased cheese protein and fat contents $(P<0.0001)$. However, protein in dry matter (PDM) and fat in dry matter (FDM) were similar, regardless of the DWPC level $(P>0.05)$. Protein retention in the curd slightly decreased when the DWPC was added to milk $(P<0.01)$. This decrease is explained by the overall better retention of milk protein than of denatured whey protein, as previously reported (Perreault et al., 2016). Fat retention in the curd remained unchanged when the DWPC was added to milk $(P>0.05)$. Standardization of cheese milk at a higher protein concentration ( $4.2 \%$ total protein in the nonfat

Table 2. Mean yield and composition of miniature cheese as influenced by the level of the denatured whey protein concentrate (DWPC) ${ }^{1}$

\begin{tabular}{|c|c|c|c|c|c|c|}
\hline \multirow[b]{2}{*}{ Item $^{2}$} & \multicolumn{4}{|c|}{ DWPC level } & \multirow[b]{2}{*}{$F$-value $(P$-value $)$} & \multirow[b]{2}{*}{$\mathrm{SE}$} \\
\hline & $0.00 \%$ & $0.25 \%$ & $0.50 \%$ & $0.75 \%$ & & \\
\hline \multicolumn{7}{|l|}{ Composition } \\
\hline Yield (\%) & $13.62^{\mathrm{D}}$ & $14.25^{\mathrm{C}}$ & $14.98^{\mathrm{B}}$ & $15.78^{\mathrm{A}}$ & $56.41(<0.0001)$ & 0.12 \\
\hline Moisture (\%) & $48.12^{\mathrm{D}}$ & $50.70^{\mathrm{C}}$ & $52.85^{\mathrm{B}}$ & $54.82^{\mathrm{A}}$ & $123.77(<0.0001)$ & 0.26 \\
\hline Protein $(\%)$ & $24.25^{\mathrm{A}}$ & $23.03^{\mathrm{B}}$ & $21.90^{\mathrm{C}}$ & $20.88^{\mathrm{D}}$ & $41.19(<0.0001)$ & 0.23 \\
\hline Fat $(\%)$ & $23.65^{\mathrm{A}}$ & $22.43^{\mathrm{B}}$ & $21.45^{\mathrm{C}}$ & $20.67^{\mathrm{D}}$ & $66.48(<0.0001)$ & 0.16 \\
\hline $\operatorname{PDM}(\%)$ & $46.72^{\mathrm{A}}$ & $46.70^{\mathrm{A}}$ & $46.43^{\mathrm{A}}$ & $46.20^{\mathrm{A}}$ & $0.41(0.7499)$ & 0.38 \\
\hline FDM $(\%)$ & $45.57^{\mathrm{A}}$ & $45.47^{\mathrm{A}}$ & $45.52^{\mathrm{A}}$ & $45.75^{\mathrm{A}}$ & $0.24(0.8668)$ & 0.25 \\
\hline MNFS (\%) & $63.00^{\mathrm{D}}$ & $65.33^{\mathrm{C}}$ & $67.30^{\mathrm{B}}$ & $69.08^{\mathrm{A}}$ & $95.39(<0.0001)$ & 0.27 \\
\hline $\mathrm{pH}$ final & $5.29^{\mathrm{A}}$ & $5.36^{\mathrm{A}}$ & $5.31^{\mathrm{A}}$ & $5.30^{\mathrm{A}}$ & $0.67(0.5816)$ & 0.04 \\
\hline \multicolumn{7}{|c|}{ Retention coefficients } \\
\hline Protein $(\%)$ & $76.88^{\mathrm{A}}$ & $76.43^{\mathrm{B}}$ & $76.25^{\mathrm{B}}$ & $76.24^{\mathrm{B}}$ & $5.73(0.0053)$ & 0.12 \\
\hline Fat $(\%)$ & $95.28^{\mathrm{A}}$ & $95.00^{\mathrm{A}}$ & $95.47^{\mathrm{A}}$ & $95.77^{\mathrm{A}}$ & $0.39(0.7589)$ & 0.52 \\
\hline \multicolumn{7}{|l|}{ Maturation } \\
\hline WSN7/TN (\%) & $7.19^{\mathrm{C}}$ & $8.23^{\mathrm{BC}}$ & $9.28^{\mathrm{B}}$ & $11.02^{\mathrm{A}}$ & $22.05(0.0003)$ & 0.35 \\
\hline
\end{tabular}

${ }^{\mathrm{A}-\mathrm{D}}$ Values within a row that do not share a common superscript differ significantly $(P<0.05)$.

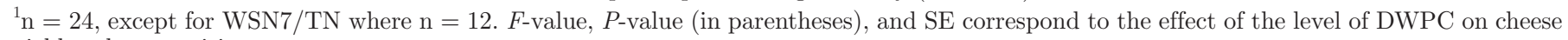
yield and composition.

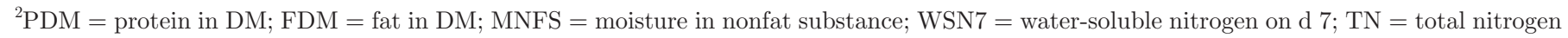
in cheese. 
fraction) allowed the formation of a paracasein network that can support a high level of denatured whey proteins without causing structural deterioration and increased fat loss in the serum (Perreault et al., 2016).

No significant difference was found for the final $\mathrm{pH}$ of the curd $(P>0.05)$, with an average of 5.31. The percentage of water-soluble nitrogen on d 7 (WSN7/TN) slightly increased with increasing DWPC level (Table $2 ; P<0.001)$. This slight increase is explained by the fact that cheeses with a higher DWPC content have a higher moisture content, which promotes proteolysis (Sahan et al., 2008; Schenkel et al., 2013). However, according to Banville et al. (2013, 2014), such a difference in the proteolysis level $(3.8 \%)$ should not drasti- cally influence the rheological properties of the cheeses measured on $\mathrm{d} 7$.

Microscopy. Confocal laser scanning images of the control cheese and of cheese containing the DWPC (0.50\% DWPC proteins in milk) are presented in Figure 2. Low magnification made it possible to observe the protein and fat distribution within the cheese matrix (Figure 2a, b). The distribution of fat versus protein is comparable to what is found in the literature for regular semihard cheeses (Auty et al., 2001; Schenkel et al., 2013; Ayala-Bribiesca et al., 2016). The close-up views make it possible to visualize the whey protein in the cheese containing DWPC (Figure 2d). The whey protein is in the form of clusters that appear whiter
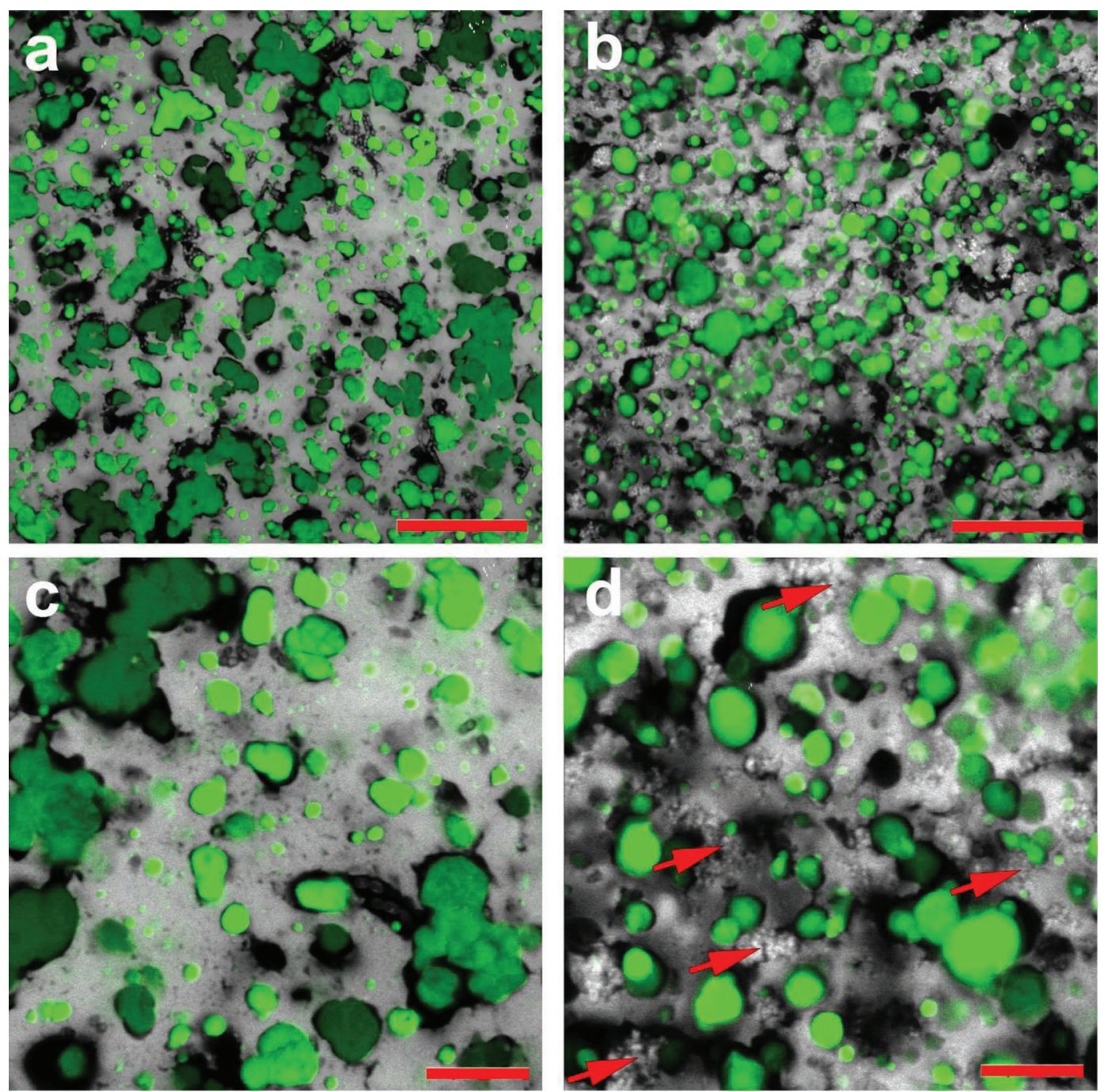

Figure 2. Confocal laser scanning images of (a and c) control cheese and (b and d) cheese containing denatured whey protein concentrate (DWPC; $0.50 \%$ DWPC proteins in milk). Gray and green pseudocolors represent protein and fat, respectively, and show their distribution within the cheese matrix. Red arrows indicate examples of denatured whey protein clusters. Bars represent $50 \mu \mathrm{m}$ for panels a and $\mathrm{b}$ and $10 \mu \mathrm{m}$ for panels c and d. 
than the rest of the protein network. These irregular areas cannot be found in the control cheese in which the protein matrix appears homogeneous (Figure 2c).

Scanning electron micrographs of the control cheese and of cheese containing the DWPC $(0.50 \%$ DWPC proteins in milk) are presented in Figure 3. Lower magnification was used to view the regularity of the cheese matrices over a larger field as well as the overall distribution (spread) of the DWPC. Higher magnification was used to more precisely characterize and compare the structure of the cheese matrices with or without the DWPC. Over a larger field, the matrices seem equally homogeneous and continuous, whether or not they contain the DWPC (Figure 3a, b). At higher magnification, the control cheese matrix still appears to be homogeneous (Figure 3c), while the cheese matrix with the addition of the DWPC has a granular appearance and appears to be more heterogeneous (Figure 3d). Large whey protein particles approximately $3 \mu \mathrm{m}$ in diameter can be observed embedded within the cheese protein matrix, giving the matrix a spongy, porous appearance in some places.

Rheometry. During cheese manufacture, a pressing-by-centrifugation method was used to generate a moisture gradient in the curd so that rheological measurements could be performed on the same cheese at different moisture contents. This approach was taken to separate the direct effect of the DWPC on cheese mechanical properties from the effect of a confounded increase in cheese moisture. As expected, cheese moisture was found to decrease with increasing distance from the rotor axis during centrifugation. The moisture difference between the lower and upper cheese samples averaged $3.7 \%$ (Table 3 ).

A frequency sweep test was conducted on cheese samples at $20^{\circ} \mathrm{C}$. The complex modulus $\left(\mathrm{G}^{*}\right)$ and the loss tangent $(\tan \delta)$ were monitored as a function of frequency, and the data were fitted to power-law models (Equations 3 and 4). The frequency dependence of these moduli was characterized by the power-law index
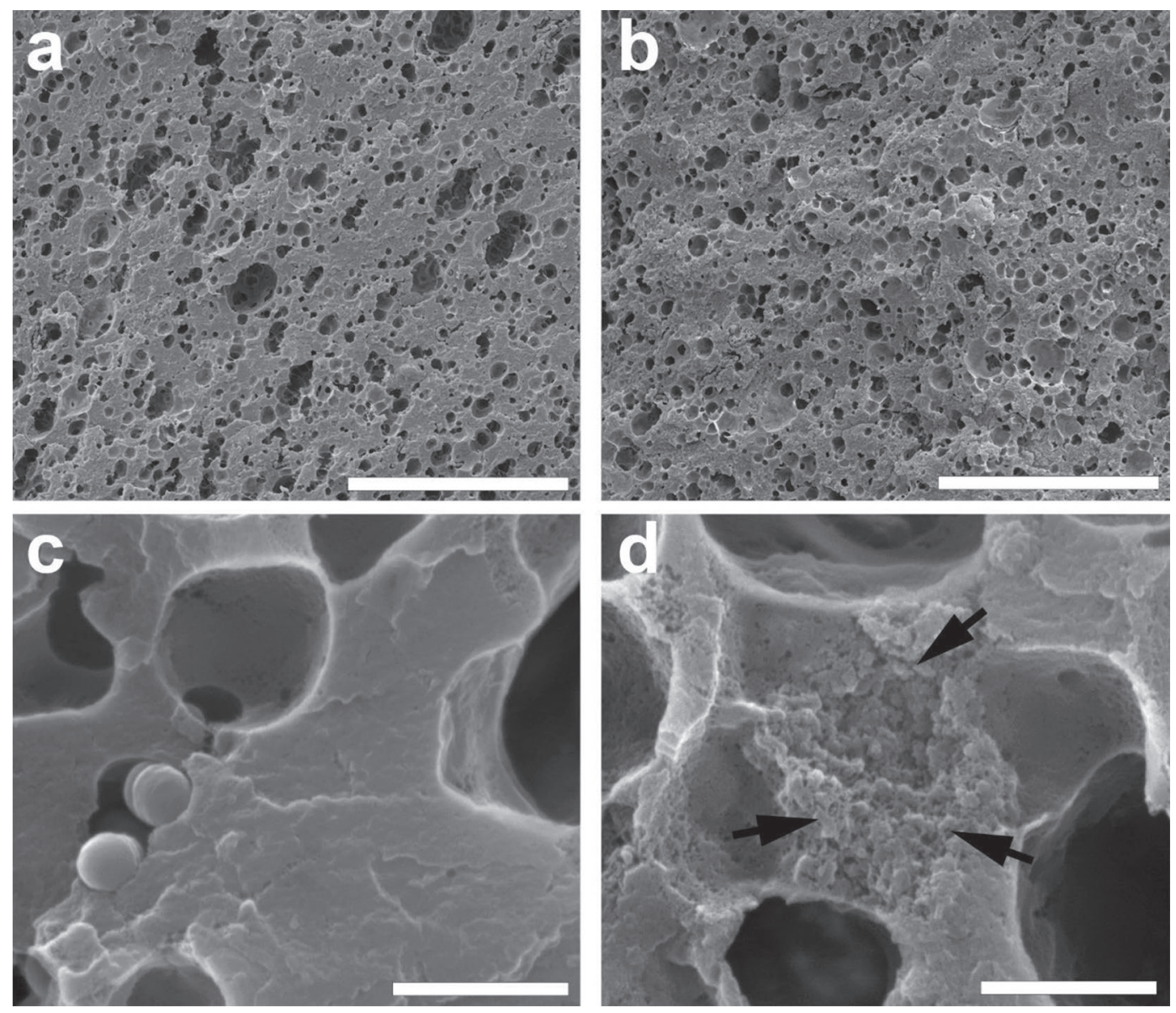

Figure 3. Scanning electron micrographs of (a and c) control cheese and (b and d) cheese containing denatured whey protein concentrate (DWPC; $0.50 \%$ DWPC proteins in milk). Black arrows indicate examples of a whey protein aggregate. Bars represent $50 \mu \mathrm{m}$ for panels a and $\mathrm{b}$ and $2 \mu \mathrm{m}$ for panels $\mathrm{c}$ and $\mathrm{d}$. 
(k) and by the values of the logarithm of $\mathrm{G}^{*}$ at $1 \mathrm{~Hz}$ and of $\tan \delta$ at $1 \mathrm{~Hz}\left(\log \mathrm{G}^{*}{ }_{1 \mathrm{~Hz}}\right.$ and $\left.\tan \delta_{1 \mathrm{~Hz}}\right)$. After the temperature was increased to $60^{\circ} \mathrm{C}$, cheese melt rheological parameters $\left(\mathrm{G}^{*}{ }_{1 \mathrm{~Hz}}\right.$ and $\left.\tan \delta_{1 \mathrm{~Hz}}\right)$ were recorded. For all rheological parameters, the statistical interaction between the 2 factors (DWPC level and sample position) was not statistically significant $(P>0.05)$. Mean rheological parameters associated with the main effects are reported in Table 3 . At $20^{\circ} \mathrm{C}$, the $\log \mathrm{G}^{*}{ }_{1 \mathrm{~Hz}}$ decreased $(P<0.0001)$ and the $\tan \delta_{1 \mathrm{~Hz}}$ increased $(P$ $<0.01$ ) with increasing DWPC concentration in milk (Table 3). Both parameters were also significantly influenced by the position of the sample in the cheese $(P$ $<0.01$ ), a result indicating that moisture has a strong effect on cheese rheology. No significant effect of the DWPC level or sample position was found on the $\mathrm{k}$ value for either the $\mathrm{G}^{*}$ or $\tan \delta(P>0.05)$. The low $\mathrm{k}$ values $(\sim 0.25)$ observed for the $\mathrm{G}^{*}$ are associated with a fast recovery of the bonds interacting in the cheese matrix upon deformation (Banville et al., 2014), which remains similar in the presence of the DWPC. For the $\tan \delta$, the low $\mathrm{k}$ values $(\sim 0.03)$ indicate that both the elastic and viscous components of the material varied in the same way with increasing frequency (Banville et al., 2014).
On average, increasing the cheese temperature from $20^{\circ} \mathrm{C}$ to $60^{\circ} \mathrm{C}$ softened the cheese and reduced the log $\mathrm{G}^{*}{ }_{1 \mathrm{~Hz}}$ by about 0.5 units. That increase in temperature also increased the $\tan \delta_{1 \mathrm{~Hz}}$ by about 0.3 units, indicating a change to a more (liquid-like) character. Cheese softening at high temperature is explained in part by the melting of fat and also by the weakening of the casein network. Increasing the temperature results in a decrease in hydrogen bonds and an increase in electrostatic repulsions. Hydrophobic interactions also increase with heating, which may reduce the contact area between casein particles as individual molecules contract on themselves (Lucey et al., 2003). Moreover, cheese softening can be promoted by an increase of free volume upon heating as observed for polymer dispersion (Liu et al., 2006).

The rheological properties of the cheese $\left(\log \mathrm{G}^{*}{ }_{1 \mathrm{~Hz}}\right.$ and $\tan \delta_{1 \mathrm{~Hz}}$ ) were plotted as a function of local moisture content in the cheese for each DWPC level (Figure 4). As previously indicated, this approach is used to isolate the direct effect of the DWPC, independent of cheese softening associated with increased moisture. At both temperatures, a linear decrease in the $\log \mathrm{G}^{*}{ }_{1 \mathrm{~Hz}}$ was observed with increasing cheese moisture content (Figure 4a). Interestingly, the values from cheese

Table 3. Mean rheological parameters of cheese as influenced by the level of the denatured whey protein concentrate (DWPC) and sample position $^{1}$

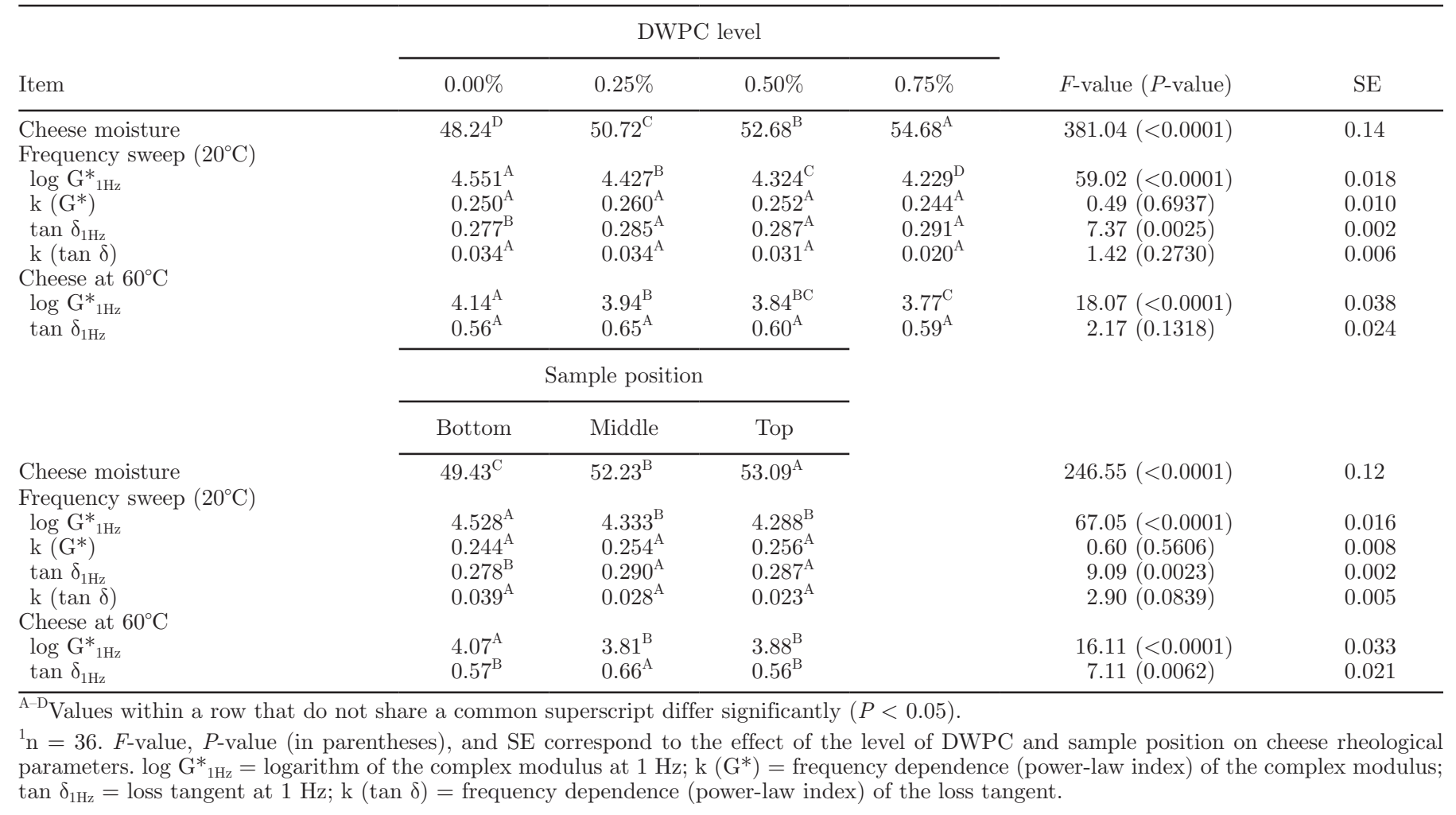


samples with different DWPC contents all fitted the same line. Microparticulated whey proteins are identified as structure breakers, introducing weak spots into the cheese matrix (Schenkel et al., 2011, 2013). They could have disrupted the 3-dimensional connectivity of the network and lower the rigidity of the matrix. Consequently, a further decrease in the $\log \mathrm{G}^{*}{ }_{1 \mathrm{~Hz}}$ was expected from the substitution of the DWPC for milk proteins, which would have resulted in distinct lines for each DWPC level in Figure 4a. However, that is not the case, and our results suggest that the effect of the DWPC on the $\log \mathrm{G}^{*}{ }_{1 \mathrm{~Hz}}$ is explained solely by changes in cheese moisture. The relationship between the tan $\delta_{1 \mathrm{~Hz}}$ and cheese moisture is presented in Figure $4 \mathrm{~b}$. At both temperatures, the tan $\delta_{1 \mathrm{~Hz}}$ slightly increased with increasing cheese moisture content (slope $\sim 0.003 \%^{-1}$ ). This increase reflects an accentuation of the viscous versus elastic character of the cheese with a higher moisture content. As was the case for the $\log \mathrm{G}^{*}{ }_{1 \mathrm{~Hz}}$, the effect of the DWPC on the tan $\delta_{1 \mathrm{~Hz}}$ seems to be explained only by the effect of the DWPC on cheese moisture. Apart from its effect on moisture content, the DWPC appears to contribute to cheese rheological properties that is similar to the contribution of caseins.

\section{Effect of DWPC Fractions}

Cheese Yield and Composition. Cheese yield and composition as a function of the DWPC fraction are presented in Table 4. The presence of the DWPC significantly increased cheese yield, from 12.5 to $15 \%$, in comparison with the control $(P \leq 0.05)$. This increase is explained mainly by the higher cheese moisture $(+4.7 \%)(P \leq 0.05)$ and, to a lesser extent, by the increased PDM $(+1.8 \%)(P \leq 0.05)$. As a result of increased moisture content, the presence of the DWPC also significantly decreased fat and protein concentrations in cheese $(P \leq 0.05)$.

Ultracentrifugation was used to separate whey protein aggregates from the total soluble component of the DWPC to evaluate their respective effect on cheese composition and cheese properties. The pellet dispersion consists of the isolated insoluble whey protein aggregates, or microparticles (fillers), from the DWPC, and the supernatant contains the soluble component, including $3.15 \%$ proteinaceous compounds (Table 1), which could not be sedimented during centrifugation. Dialysis was used to isolate the soluble mineral component of the DWPC (diffusible component). The composition and characteristics of the DWPC fractions were presented in a previous study (Perreault et al., 2017), and some of that information is reported in Table 1.

The presence of the pellet dispersion significantly increased cheese yield $(+1.8 \%)$, cheese moisture $(+3.1 \%)$, and PDM $(+1.9 \%)$ compared with the control $(P \leq$ 0.05). Higher cheese moisture and PDM with the pellet dispersion, as with the DWPC, can be explained in part by the presence of microparticles (sedimentable whey protein aggregates) that are integrated into the casein network and restrict whey drainage through their good water-binding capacity (Hinrichs, 2001; Schenkel et al., 2011); moreover, because they are additional filler elements in the gelled matrix, these microparticles could
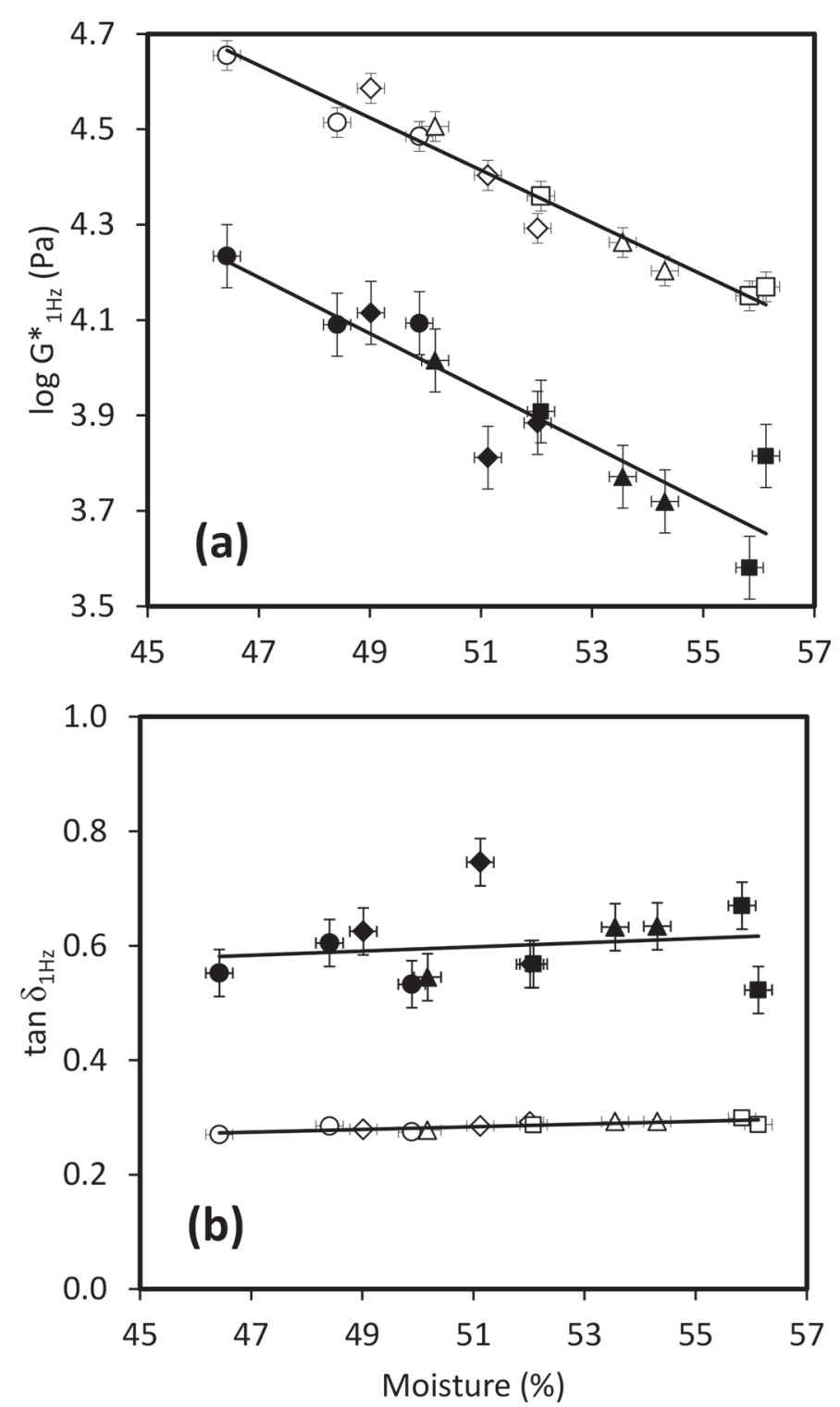

Figure 4. Combined effect of cheese milk fortification with denatured whey protein concentrate (DWPC) and local moisture content in cheese on rheological parameters: (a) the logarithm of the complex modulus at $1 \mathrm{~Hz}\left(\log \mathrm{G}^{*}{ }_{1 \mathrm{~Hz}}\right)$, and (b) the loss tangent at $1 \mathrm{~Hz}$ (tan $\delta_{1 \mathrm{~Hz}}$ ). The DWPC protein levels in milk (wt/wt) were $0 \%$ (circles), $0.25 \%$ (diamonds), $0.50 \%$ (triangles), and $0.75 \%$ (squares). Rheological parameters were recorded at $20^{\circ} \mathrm{C}$ (open symbols) and $60^{\circ} \mathrm{C}$ (closed symbols). Error bars correspond to standard errors. 
restrict whey drainage through a pore-blocking effect, an effect that is recognized in the case of fat globules (Guinee et al., 2007; Schenkel et al., 2011). The higher magnitude of the effect on cheese yield and cheese moisture for the DWPC than for the pellet dispersion in comparison with the control suggests that, aside from the microparticles, another component of the whole ingredient contributed to the increase in these parameters. Cheese yield, cheese moisture, and other cheese composition parameters were not significantly influenced by the DWPC dialysate in comparison with the control $(P \leq 0.05)$. The diffusible fraction of the DWPC could therefore not explain the difference between the effect of the whole DWPC and the effect of the pellet dispersion on cheese yield and composition. However, the supernatant significantly increased cheese yield $(+0.5 \%)$ and cheese moisture $(+1.3 \%)$ in comparison with the control $(P \leq 0.05)$, without having any significant effect on PDM $(P>0.05)$. These results suggest that the increased cheese moisture is entirely responsible for the increased cheese yield in the presence of the supernatant. This effect could be explained by the decreased contraction capacity of rennet gel in the presence of soluble, nondiffusible components found in the supernatant (Perreault et al., 2017). Small whey protein complexes likely interact with casein micelles, which may limit gel structure rearrangement and contraction (Giroux et al., 2015) during the cheese-making process and ultimately limit overall whey expulsion from cheese. No significant effect on fat retention in the curd was found when any of the DWPC fractions were used $(P>0.05)$. However, protein retention was significantly influenced by the DWPC fractions and ranks as follows: pellet dispersion $(78.1 \%)>$ dialysate
$(77.0 \%)=$ milk dialysate $(76.9 \%)>\operatorname{DWPC}(76.3 \%)>$ supernatant $(74.0 \%)$.

Rheometry. A second set of experiments used the same procedure that was used for the experiment on the DWPC levels; namely, pressing-by-centrifugation and rheological measurements at 3 different cheese moisture levels for each cheese. As expected, cheese moisture decreased with increasing distance from the rotor axis during centrifugation. The moisture gradient was similar to that observed in the first experiment with a difference between the lower and upper cheese samples of $3.9 \%$ (Table 5). A frequency sweep test and a temperature sweep test were conducted. Here again, for all rheological parameters, the statistical interaction between the 2 factors (DWPC fraction and sample position) was not significant $(P>0.05)$. Mean rheological parameters associated with the main effects are reported in Table 5. The $\log \mathrm{G}^{*}{ }_{1 \mathrm{~Hz}}$ at $20^{\circ} \mathrm{C}$ was the only parameter significantly affected by both the DWPC fraction $(P \leq 0.0001)$ and the sample position $(P \leq 0.0001)$. No other parameters were significantly influenced by the DWPC fractions $(P>0.05)$.

As was the case for the experiment on the DWPC levels, the $\log \mathrm{G}^{*}{ }_{1 \mathrm{~Hz}}$ was plotted as a function of local moisture content in cheese for each DWPC fraction (Figure 5). On average, increasing the cheese temperature from 20 to $60^{\circ} \mathrm{C}$ softened the cheese and reduced the $\log \mathrm{G}^{*}{ }_{1 \mathrm{~Hz}}$ by about 0.5 units. At both temperatures, a decrease in the $\log \mathrm{G}^{*}{ }_{1 \mathrm{~Hz}}$ was observed with increasing cheese moisture content, which again indicates that moisture has a strong effect on cheese rheology. Interestingly, the values from cheese samples with different DWPC fractions seemed to fit 2 distinct lines. Linear regressions were drawn separately for the control data

Table 4. Mean yield and composition of miniature cheese as influenced by the denatured whey protein concentrate (DWPC) fractions ${ }^{1}$

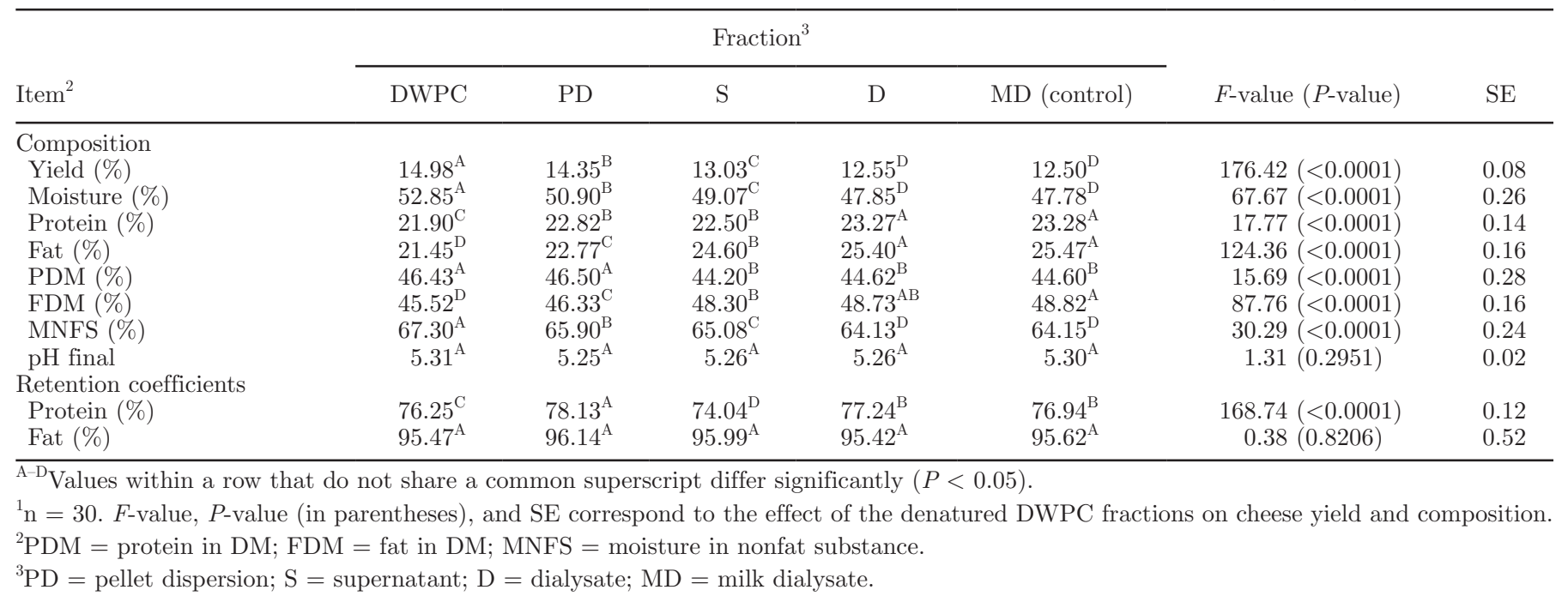




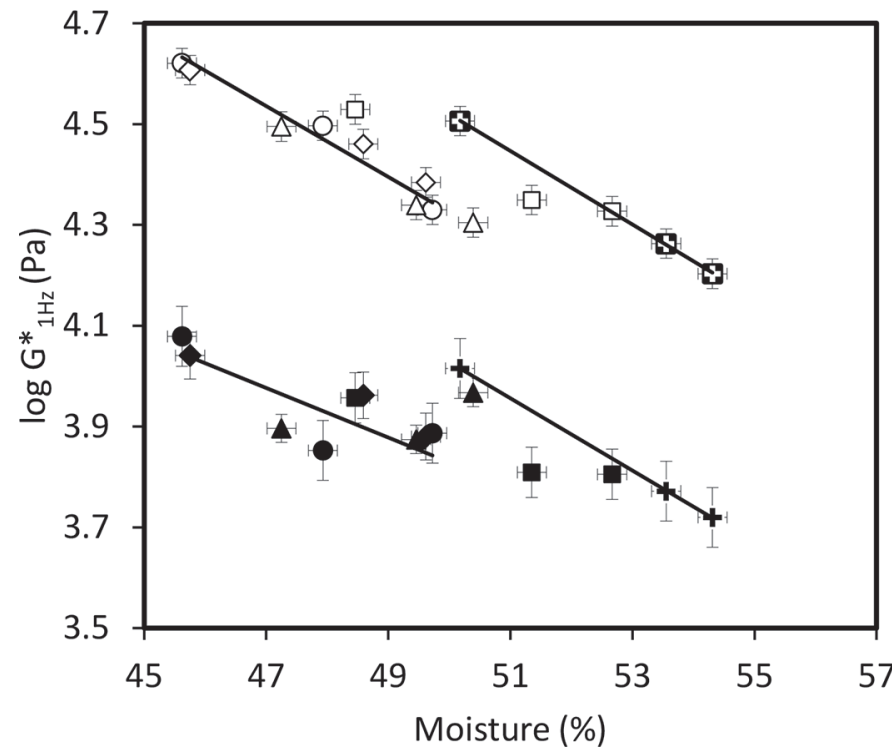

Figure 5. Combined effect of the fraction of denatured whey protein concentrate (DWPC) added to cheese milk and the local moisture content in cheese on the logarithm of the complex modulus at $1 \mathrm{~Hz}$ $\left(\log \mathrm{G}^{*}{ }_{1 \mathrm{~Hz}_{z}}\right)$. The DWPC fractions were DWPC (crosses), pellet dispersion (squares), supernatant (triangles), and dialysate (diamonds), and milk dialysate (circles) was used as a control. Rheological parameters were recorded at $20^{\circ} \mathrm{C}$ (open symbols) and $60^{\circ} \mathrm{C}$ (closed symbols). Error bars correspond to standard errors. and the DWPC data, and they revealed that, for an equal cheese moisture content, the addition of DWPC to cheese milk tends to increase the rigidity of the matrix in comparison with the control. This finding is consistent with the results reported in the previous section that suggest that the contribution of the DWPC to cheese rheological properties was similar to the contribution of caseins. Although the dialysate and supernatant data are grouped with the control data in Figure 5, the pellet dispersion data are closer to the DWPC data. The sedimentable aggregates therefore appear to be the main component contributing to the increased rigidity of cheese in the presence of the DWPC.

We could hypothesize that sedimentable aggregates, or denatured whey protein microparticles, act as active fillers in the cheese matrix. The sedimentable aggregates, isolated in the pellet dispersion, occupy a volume fraction of about 0.02 in milk, as estimated from the measured voluminosity (Table 1 ). That volume fraction is added to the volume fraction of 0.04 that is generally occupied by fat globules in experimental milk. In a "filled gel," such as cheese, the characteristics and volume fraction of the fillers could influence the shear moduli (Barden et al., 2015). A general assumption about filled gels is that their shear modulus $\left(\mathbf{G}_{\mathrm{m}+\mathrm{f}}\right)$

Table 5. Mean rheological parameters of cheese as influenced by the denatured whey protein concentrate (DWPC) fractions and sample position

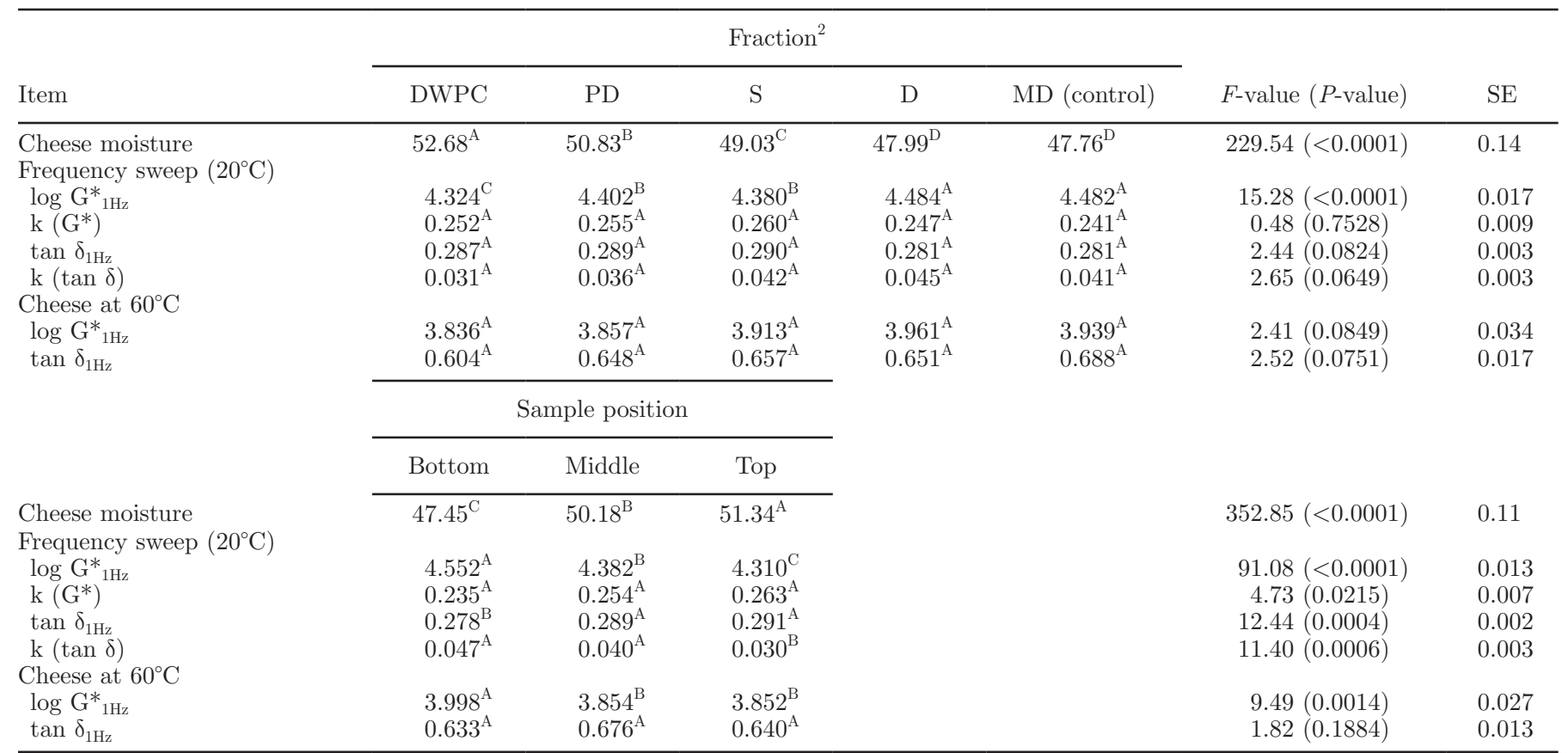

${ }^{\mathrm{A}-\mathrm{D}}$ Values within a row that do not share a common superscript differ significantly $(P<0.05)$.

${ }^{1} \mathrm{n}=45 . F$-value, $P$-value (in parentheses), and SE correspond to the effect of the DWPC fractions and sample position on cheese rheological parameters. $\log \mathrm{G}^{*}{ }_{1 \mathrm{~Hz}}=\operatorname{logarithm}$ of the complex modulus at $1 \mathrm{~Hz} ; \mathrm{k}\left(\mathrm{G}^{*}\right)=$ frequency dependence (power-law index) of the complex modulus; $\tan \delta_{1 \mathrm{~Hz}}=$ loss tangent at $1 \mathrm{~Hz} ; \mathrm{k}(\tan \delta)=$ frequency dependence (power-law index) of the loss tangent.

${ }^{2} \mathrm{PD}=$ pellet dispersion; $\mathrm{S}=$ supernatant; $\mathrm{D}=$ dialysate; $\mathrm{MD}=$ milk dialysate. 
is proportional to the shear moduli of the gel matrix phase $\left(\mathbf{G}_{\mathbf{m}}\right)$ and filler phase $\left(\mathbf{G}_{\mathbf{f}}\right)$ and the volume fractions of each phase $\left(\phi_{\mathrm{m}}+\phi_{\mathrm{f}}=1\right.$; Barden et al., 2015). The shear modulus of filled gels is also dependent on the nature of the interaction between filler particles and the matrix: "inactive" (i.e., non-interacting) fillers would essentially act as holes in the matrix, contributing to decreased the shear modulus as the concentration of fillers increases, whereas "active" (i.e., interacting) filler particles can connect to the matrix and can increase $\left(G_{f}>G_{m}\right)$, decrease $\left(G_{f}<G_{m}\right)$, or not change $\left(G_{\mathrm{f}}=\mathrm{G}_{\mathrm{m}}\right)$ the shear modulus depending on the relative magnitudes of the filler and gel moduli (Barden et al., 2015). The whey protein aggregates used in the current study have already been considered to be essentially non-interacting filler particles in a rennet milk gel (Perreault et al., 2017): The presence of whey protein aggregates in cheese milk was found to only slightly decrease the gel storage modulus $\left(\mathrm{G}^{\prime}\right) 60 \mathrm{~min}$ after renneting. It seems that the behavior of whey protein aggregates depends on the cheese processing step. When these denatured whey protein fillers are in a loose rennet gel, surrounded by a thick hydration layer, they behave as non-interacting fillers (van Vliet, 1988); but when these denatured whey protein fillers are in a further drained and compressed matrix after pressing, they interact with the casein network (active fillers) and help increase its rigidity. This hypothesis is in agreement with Barden et al. (2015), who found a reinforcing effect on cheese structure when the volume fraction of filler particles (i.e., nonmelted fat globules or Sephadex beads) was increased.

\section{CONCLUSIONS}

We evaluated the effect of the DWPC level on cheese yield and composition, and characterized the contribution of the different fractions of the DWPC to its effect. The information generated could guide manufacturers in optimizing the production of effective DWPC for cheese production. Furthermore, a pressing-by-centrifugation method was used to produce cheese samples with the same solids composition but variable moisture contents. This approach made it possible to separate the direct contribution of the DWPC to cheese rheological properties from the contribution of moisture. The results revealed that, when similar cheese moisture contents are obtained by modulating the pressing conditions, the contribution of the DWPC proteins to cheese rheological properties is similar to the contribution of caseins. Using the same approach to study the effect of the different fractions of the DWPC on the rheological properties provided a better understanding of the contribution of the DWPC to cheese rigidity: microparticulated whey proteins appear to act as active fillers in pressed cheese, conferring some rigidity. These results indicate that microparticulated whey proteins could be used not only as a fat replacer in cheese, as they are already recognized as being, but also as an ingredient to partly replace casein. This knowledge could be further developed by using the same method to evaluate the effect of DWPC on other mechanical properties of cheese, such as its behavior under large deformations, as well as on cheese functional properties.

\section{ACKNOWLEDGMENTS}

This work was financially supported by the Natural Sciences and Engineering Research Council of Canada (Ottawa, ON, Canada) and Agropur Dairy Cooperative (Saint-Hubert, QC, Canada). The authors thank Marine Havard (trainee) for her assistance in carrying out the experiments and Vincent Banville (Agropur Dairy Cooperative) for his help during the preparation of microscopy samples.

\section{REFERENCES}

AOAC International. 2005a. Nitrogen (total) in milk, Method No. 991.20. Official Methods of Analysis of AOAC International. 18th ed. W. Horwitz, ed. AOAC International, Gaithersburg, MD.

AOAC International. 2005b. Solids (total) in milk, Method No. 990.20. Official Methods of Analysis of AOAC International. 18th ed. W. Horwitz, ed. AOAC International, Gaithersburg, MD.

Auty, M. A. E., M. Twomey, T. P. Guinee, and D. M. Mulvihill. 2001. Development and application of confocal scanning laser microscopy methods for studying the distribution of fat and protein in selected dairy products. J. Dairy Res. 68:417-427.

Ayala-Bribiesca, E., M. Lussier, D. Chabot, S. L. Turgeon, and M. Britten. 2016. Effect of calcium enrichment of Cheddar cheese on its structure, in vitro digestion and lipid bioaccessibility. Int. Dairy J. 53:1-9.

Banks, J. M., and D. D. Muir. 1985. Effect of incorporation of denatured whey protein on the yield and quality of Cheddar cheese. Int. J. Dairy Technol. 38:27-32.

Banville, V., P. Morin, Y. Pouliot, and M. Britten. 2013. Physical properties of pizza Mozzarella cheese manufactured under different cheese-making conditions. J. Dairy Sci. 96:4804-4815.

Banville, V., P. Morin, Y. Pouliot, and M. Britten. 2014. Shreddability of pizza Mozzarella cheese predicted using physicochemical properties. J. Dairy Sci. 97:4097-4110.

Barden, L. M., J. A. Osborne, D. J. McMahon, and E. A. Foegeding. 2015. Investigating the filled gel model in cheddar cheese through use of Sephadex beads. J. Dairy Sci. 98:1502-1516.

Dalgleish, D. G. 1983. Coagulation of renneted bovine casein micelles: Dependence on temperature, calcium ion concentration and ionic strength. J. Dairy Res. 50:331-340.

Desai, N., and J. Nolting. 1995. Microstructure studies of reduced-fat cheeses containing fat substitute. Pages 295-302 in Chemistry of Structure-Function Relationships in Cheese. E. L. Malin and M. H. Tunick, ed. Springer Science+Business Media, New York.

Fenelon, M. A., and T. P. Guinee. 1997. The compositional, textural and maturation characteristics of reduced-fat Cheddar made from milk containing added Dairy-Lo ${ }^{\text {TM }}$. Milchwissenschaft 52:385-389.

Giroux, H. J., G. Lanouette, and M. Britten. 2015. Effect of whey protein aggregates of various sizes on the formation and properties of rennet-induced milk gels. Food Hydrocoll. 45:272-278. 
Guinee, T. P., E. O. Mulholland, J. Kelly, and D. J. O. Callaghan. 2007. Effect of protein-to-fat ratio of milk on the composition, manufacturing efficiency, and yield of Cheddar cheese. J. Dairy Sci. 90:110-123.

Hinrichs, J. 2001. Incorporation of whey proteins in cheese. Int. Dairy J. 11:495-503.

Joshi, N. S., K. Muthukumarappan, and R. I. Dave. 2003. Understanding the role of calcium in functionality of part skim Mozzarella cheese. J. Dairy Sci. 86:1918-1926.

Kethireddipalli, P., A. R. Hill, and D. G. Dalgleish. 2010. Protein interactions in heat-treated milk and effect on rennet coagulation. Int. Dairy J. 20:838-843.

Kethireddipalli, P., A. R. Hill, and D. G. Dalgleish. 2011. Interaction between casein micelles and whey protein/ $/$-casein complexes during renneting of heat-treated reconstituted skim milk powder and casein micelle/serum mixtures. J. Agric. Food Chem. 59:14421448.

Lebeuf, Y., C. Lacroix, and P. Paquin. 1998. Effet de l'incorporation des protéines du lactosérum dénaturées et microparticulées dans le cheddar jeune. Lait 78:303-318.

Liu, C. Y., J. He, R. Keunings, and C. Bailly. 2006. New linearized relation for the universal viscosity - Temperature behavior of polymer melts. Macromolecules 39:8867-8869.

Lucey, J. A., and P. F. Fox. 1993. Importance of calcium and phosphate in cheese manufacture: A review. J. Dairy Sci. 76:1714-1724.

Lucey, J. A., M. E. Johnson, and D. S. Horne. 2003. Invited review: Perspectives on the basis of the rheology and texture properties of cheese. J. Dairy Sci. 86:2725-2743.

McMahon, D. J., M. C. Alleyne, R. L. Fife, and C. J. Oberg. 1996. Use of fat replacers in low fat Mozzarella cheese. J. Dairy Sci. 79:1911-1921.

Mead, D., and P. Roupas. 2001. Effect of incorporation of denatured whey proteins on chemical composition and functionality of pizza cheese. Aust. J. Dairy Technol. 56:19-23.

Morin, P., Y. Pouliot, and M. Britten. 2008. Effect of buttermilk made from creams with different heat treatment histories on properties of rennet gels and model cheeses. J. Dairy Sci. 91:871-882.

Perreault, V., P. Morin, Y. Pouliot, and M. Britten. 2017. Effect of denatured whey protein concentrate and its fractions on rennetinduced milk gels. Int. Dairy J. 64:48-55.
Perreault, V., O. Turcotte, P. Morin, Y. Pouliot, and M. Britten. 2016 Combined effect of denatured whey protein concentrate level and fat level in milk on rennet gel properties. Int. Dairy J. 55:1-9.

Sahan, N., K. Yasar, A. A. Hayaloglu, O. B. Karaca, and A. Kaya. 2008. Influence of fat replacers on chemical composition, proteolysis, texture profiles, meltability and sensory properties of low-fat Kashar cheese. J. Dairy Res. 75:1-7.

Sandra, S., M. Ho, M. Alexander, and M. Corredig. 2012. Effect of soluble calcium on the renneting properties of casein micelles as measured by rheology and diffusing wave spectroscopy. J. Dairy Sci. 95:75-82.

Schenkel, P., R. Samudrala, and J. Hinrichs. 2011. Fat-reduced semihard cheese enriched with a microparticulated whey protein concentrate: Impact on cheese-making properties and rheological characteristics. Milchwissenschaft 66:43-47.

Schenkel, P., R. Samudrala, and J. Hinrichs. 2013. The effect of adding whey protein particles as inert filler on thermophysical properties of fat-reduced semihard cheese type Gouda. Int. J. Dairy Technol. $66: 220-230$.

Steffl, A., M. Hafenmair, A. Hechler, and J. Hinrichs. 1999. Influence of whey protein particles on the renneting properties of milk. Milchwissenschaft 54:510-513.

Subramanian, R., K. Muthukumarappan, and S. Gunasekaran. 2006. Linear viscoelastic properties of regular- and reduced-fat pasteurized process cheese during heating and cooling. Int. J. Food Prop. 9:377-393.

van Vliet, T. 1988. Rheological properties of filled gels. Influence of filler matrix interaction. Colloid Polym. Sci. 266:518-524.

Watkinson, P., C. Coker, R. Crawford, C. Dodds, K. Johnston, A. McKenna, and N. White. 2001. Effect of cheese pH and ripening time on model cheese textural properties and proteolysis. Int. Dairy J. 11:455-464.

Wodecki, E., J. Budny, K. W. Hoppe, A. Gryzowska, and J. Turowski. 1984. Effect of water content on the hardness of Edam cheese. J. Food Eng. 3:295-305.

Yang, X., N. R. Rogers, T. K. Berry, and E. A. Foegeding. 2011. Modeling the rheological properties of cheddar cheese with different fat contents at various temperatures. J. Texture Stud. 42:331-348. 